\title{
The Japanese Translation of the Meaning in Life Questionnaire-Short Form: Reliability and Construct Validity
}

\author{
Katsunori Sumi \\ Graduate School of Engineering, Nagoya Institute of Technology, Nagoya, Japan \\ Email: sumi@nitech.ac.jp
}

How to cite this paper: Sumi, K. (2019). The Japanese Translation of the Meaning in Life Questionnaire-Short Form: Reliability and Construct Validity. Psychology, 10, 2266-2276.

https://doi.org/10.4236/psych.2019.1016143

Received: November 1, 2019

Accepted: December 27, 2019

Published: December 30, 2019

Copyright $\odot 2019$ by author(s) and Scientific Research Publishing Inc. This work is licensed under the Creative Commons Attribution International License (CC BY 4.0).

http://creativecommons.org/licenses/by/4.0/

\section{(c) (i) Open Access}

\begin{abstract}
The purpose of this study was to evaluate the reliability and construct validity of a Japanese translation of the Meaning in Life Questionnaire-Short Form (MLQ-SF-J), a brief self-report measure of the presence of meaning in life. Data were collected from two samples of 382 Japanese college students (177 women, 205 men; mean age $=20.92$ years, $S D=0.66)$ and 407 Japanese adult workers (196 women, 211 men; mean age $=38.83$ years, $S D=9.88$ ). Exploratory factor analysis clearly supported the expected one-factor structure of the MLQ-SF-J in both samples. The MLQ-SF-J was found to have good internal consistency reliability in both samples (Cronbach's alphas $=0.80$ and 0.86 ) and 4-week test-retest reliability in the student sample $(r=0.70)$. As expected, moderate correlations with hedonic well-being scores and high correlations with eudaimonic well-being scores were generally found in both samples. Correlations between scores on the MLQ-SF-J and a purpose in life scale were also high, as expected. The MLQ-SF-J was found to be a reliable and valid measure useful for a large-scale research on purpose in life in the Japanese population.
\end{abstract}

\section{Keywords}

Meaning in Life, Meaning in Life Questionnaire-Short Form, Japanese

Translation, Reliability, Construct Validity, College Student, Adult Worker

\section{Introduction}

\subsection{Meaning in Life: Relationships with Well-Being and Definition}

Meaning in life has received increasing and renewed attention with the growing focus on positive psychology (Ryan \& Deci, 2001; Seligman \& Csikszentmihalyi, 
2000). In positive psychology, as well as humanistic psychology, it is commonly assumed that experiencing meaning in life is a fundamental element of human functioning and the good life (Heintzelman \& King, 2014a; Ryan \& Deci, 2001; Ryff \& Singer, 1998). One reason is that in the last several decades, an impressive number of studies have found that the experience of meaning in life substantially contributes to well-being and health (Heintzelman \& King, 2014a; Steger, 2009, 2012). Meaning in life is thus an important domain for understanding well-being (Deci \& Ryan, 2008; Diener \& Seligman, 2004; Ryff \& Singer, 1998).

There are two distincts, yet related theoretical traditions of well-being: hedonic well-being and eudaimonic well-being (Keyes, Shmotkin, \& Ryff, 2002; Ryan \& Deci, 2001; Waterman, 1993). Hedonic well-being has been specified in terms of three aspects: life satisfaction as a cognitive aspect, the presence of positive affect, and the absence of negative affect as affective aspects (Deci \& Ryan, 2008; Diener, Lucas, \& Scollon, 2006). In contrast, eudaimonic well-being focuses on psychological flourishing and personal growth (Keyes et al., 2002; Ryan \& Deci, 2001; Ryff \& Keyes, 1995). Although meaning in life itself is neither hedonic nor eudaimonic (Steger, Shin, Shim, \& Fitch-Martin, 2013), it has been considered a core component of eudaimonic well-being (Keyes, Shmotkin, \& Ryff, 2002; Ryff \& Keyes, 1995; Steger, 2009). Hence, meaning in life has a closer association with eudaimonic well-being than hedonic well-being (Heintzelman \& King, 2014a; Steger, 2012).

Despite general agreement on the importance of meaning in life for well-being and humanity, a unifying theoretical framework is lacking, and hence numerous definitions regarding meaning in life have been proposed (Heintzelman \& King, 2014a; Steger, 2012; Steger, Frazier, Oishi, \& Kaler, 2006). As a definition broadly encompassing the major definitions of meaning in life, Steger et al. (2006: p. 81) suggested "the sense made of, and significance felt regarding, the nature of one's being and existence". Recently, three central components of meaning in life have been advocated: a sense of purpose in goal directions, a sense of significance about mattering, and a sense of coherence about one's life making sense (Heintzelman \& King, 2014a, 2014b; Martela \& Steger, 2016). Additionally, researchers have typically examined the two principal dimensions of meaning in life: presence of meaning and search for meaning (Bloch, Farrell, Hook, Van Tongeren, Penberthy, \& Davis, 2017). The presence of meaning refers to the degree to which people feel that their life is meaningful, whereas the search for meaning refers to the degree to which people seek out meaning in their lives (Bloch et al., 2017; Steger et al., 2006).

\subsection{Measures of Meaning in Life}

Although there are many measures of meaning in life reflecting the numerous definitions that have been offered, most studies have used one of three measures (Steger et al., 2006): the Purpose in Life Test (Crumbaugh \& Maholick, 1964), the Life Regard Index (Battista \& Almond, 1973), and the Meaning Scale of the 
Sense of Coherence (Antonovsky, 1987). After Steger et al. (2006) criticized these existing measures as having characteristics that muddle the nomological network of meaning, they developed a new measure of meaning in life, the Meaning in Life Questionnaire (MLQ).

The MLQ is a 10-item measure that has been widely used by many researchers comprising two 5-item subscales to assess either presence of meaning or search for meaning. Items are rated on a 7-point scale ranging from 1 (absolutely untrue) to 7 (absolutely true). The total score for each subscale is simply the sum of all the item scores. The range of possible scores is 5 to 35 , with higher scores indicating greater meaning in life. Each subscale showed good internal consistency reliability and good test-retest reliability over one month (Steger et al., 2006). Items comprising each subscale loaded onto two separate factors. The convergent and discriminant validity of both subscales was supported by a multitrait-multimethod approach as well as by simple correlations between scores on the subscales and various variables (Steger et al., 2006). The MLQ is also available in Japanese (Steger, Kawabata, Shimai, \& Otake, 2008).

In addition, there is a short form of the presence subscale, called the Meaning in Life Questionnaire-Short Form (MLQ-SF: Steger \& Samman, 2012). The MLQ-SF consists of three items that slightly modified the items chosen from the MLQ. Each item is rated on a 4-point scale ranging from 1 (Not at all true) to 4 (Completely true). The total score is the sum of all the item scores. The range of possible scores is 3 to 12 , with higher scores indicating the greater presence of meaning in life. The Spanish translation of the original MLQ-SF (English version) was validated using data from Chilean adults (Steger \& Samman, 2012). The Spanish translation showed a one-factor structure and good internal consistency reliability. Construct validity was supported by the relationships with well-being indices, including basic psychological needs satisfaction, life satisfaction, and domain satisfaction.

The influence of cultural context on meaning in life has been pointed out (Heintzelman \& King, 2014a; Steger et al., 2008; Steger \& Samman, 2012). For example, it has found that American samples had higher scores on the presence subscale of the MLQ than Japanese samples (Steger et al., 2008). However, most of the research on meaning in life has been conducted in industrialized Western nations (Steger \& Samman, 2012), and thus cross-cultural understanding of meaning in life requires more research in other nations including Japan. For this purpose, a reliable and valid measure, particularly a brief one useful in large-scale research, is needed to assess meaning in life.

\subsection{The Purpose of This Study}

The purpose of this study was to examine the reliability and construct validity of the MLQ-SF translated into Japanese (MLQ-SF-J) so as to make it available for large-scale research. Data were collected from two samples: Japanese college students and adult workers. To assess test-retest reliability, only the college stu- 
dents completed the MLQ-SF-J twice at a 4-week interval. Although meaning in life is closely related to well-being, a closer relationship is expected to eudaimonic well-being than hedonic well-being, which should be rather weak (Steger \& Kashdan, 2007). For example, Steger \& Samman (2012) found a moderate correlation $(r=.43)$ between the MLQ-SF and life satisfaction scores. For this reason, it was assumed that the MLQ-SF-J scores would be moderately correlated with scores for hedonic well-being but highly correlated with scores for eudaimonic well-being.

In some previous studies, meaning in life has been treated as a distinct construct from purpose in life (George \& Park, 2013; Scheier, Wrosch, Baum, Cohen, Martire, Matthews, Schulz, \& Zdaniuk, 2006). Other studies have considered these to be interchangeable or overlapping constructs (George \& Park, 2013; Ryff \& Keyes, 1995; Martela \& Steger, 2016). In particular, Item 1 of the MLQ-SF, "My life has a clear meaning or purpose", does not clearly distinguish between meaning and purpose. Hence, the MLQ-SF-J scores should be highly correlated with scores for purpose in life. Additionally, it was expected that the MLQ-SF-J scores would be negatively correlated with scores on negative affect measures and positively correlated with the other scores.

\section{Method}

\subsection{Participants}

There were two samples of participants in this study. Sample A consisted of 382 Japanese students ( 177 women and 205 men) from two colleges in urban areas of Japan. The mean age was 20.92 years ( $S D=0.66$, range 20 to 22 years). Sample B consisted of 407 full-time working adults (196 women and $211 \mathrm{men}$ ). Their mean age was 38.83 years ( $S D=9.88$, range 22 to 59 years), and they had a variety of occupations, mainly clerical (36.5\%), factory (29.8\%), and sales (14.6\%). Most of them worked in urban areas in Japan.

\subsection{Measures}

\subsubsection{Meaning in Life Questionnaire-Short Form}

The original MLQ-SF was translated from English into Japanese using a translation and back-translation procedure (Brislin, 1970). One bilingual researcher translated the items of the MLQ-SF into Japanese, and the other bilingual researcher translated the items from Japanese into English. Consistency between the translation and the back translation was then checked by the two researchers. This process was followed repeatedly until an acceptable degree of consistency was achieved. Cultural relevance and item difficulty had little influence on the translation process because the items of the original MLQ-SF are written plainly and express experiences familiar to Japanese people. After the process was complete, three graduate students confirmed that they had no problem understanding the translated items. The Japanese translation of the MLQ-SF (MLQ-SF-J) used the same 4-point response format as the original MLQ-SF. 


\subsubsection{Well-Being Measures}

1) Life satisfaction

The Japanese version of the 5-item Satisfaction with Life Scale (Diener, Emmons, Larsen, \& Griffin, 1985; Sumi, 2008) was used to measure life satisfaction. The Japanese version uses a 5-point response format ranging from 1 (strongly disagree) to 5 (strongly agree). Good internal consistency reliability (Cronbach's alpha $=0.84)$ and factorial validity, identifying a single factor structure, were supported for the Japanese version (Sumi, 2008).

2) Positive and negative affect

Positive and negative affect was assessed using the Japanese version of the 12-item Scale of Positive and Negative Experience (Diener et al., 2010; Sumi, 2013 , 2014). This scale has a 6-item positive affect subscale and a 6-item negative affect subscale. The items use a 5-point response format ranging from 1 (very rarely or never) to 5 (very often or always). The subscales had good internal consistency reliability (Cronbach's alphas $=0.86$ to 0.93 ) and test-retest reliability over one month ( $r \mathrm{~s}=0.60$ and 0.57 ), and the items loaded onto two separate factors (Sumi, 2013, 2014). Convergent validity was supported by correlations with scores on several well-being measures (Sumi, 2013).

3) Eudaimonic well-being

Psychosocial flourishing as eudaimonic well-being was measured using the Japanese version of the 8-item Flourishing Scale (Diener et al., 2010; Sumi, 2013, 2014). The items of this measure describe broad and important aspects of human functioning, and are rated on a 7-point Likert scale ranging from 1 (strongly disagree) to 7 (strongly agree). Good internal consistency reliability (Cronbach's alphas $=0.94$ to 0.95 ) and test-retest reliability over one month ( $r=$ 0.87) were obtained (Sumi, 2013, 2014). A single factor structure was found as expected (Sumi, 2013). Correlations with scores on several well-being measures supported convergent validity of the Japanese version (Sumi, 2013).

4) Purpose in life

To assess purpose in life, the Japanese version of the 6-item Life Engagement Test was used (Scheier et al., 2006; Sumi, 2018). The items of this measure are rated on a 5-point scale ranging from 1 (strongly disagree) to 5 (strongly agree). Half of the items are reverse scored to yield a total scale score. The measure has good internal consistency reliability (Cronbach's alphas $=0.82$ to 0.86 ), test-retest reliability over one month $(r=0.76)$, and a single factor structure as expected (Sumi, 2018). Acceptable convergent validity was supported by correlations with scores on several well-being measures (Sumi, 2013). Construct validity was supported through correlations with scores on the well-being measures (Sumi, 2013).

\subsection{Procedure of Questionnaire Administration}

All the students in Sample A participated in two questionnaire sessions separated by a 4 -week interval (Time 1 and Time 2). They completed the MLQ-SF-J at Time 1 and Time 2 and other measures only at Time 1 . The adult workers in Sample B completed all the measures in one questionnaire session. All the par- 
ticipants voluntarily took part in this study after giving informed consent. Ethical clearance for the study was obtained from the relevant ethical committee.

\subsection{Data Analysis}

First, to examine the factor structure of the MLQ-SF-J, exploratory factor analysis using principal axis factoring was conducted using the data from each sample. Although confirmatory factor analysis is generally needed to confirm the factor structure of the MLQ-SF-J, this analysis was not performed in this study because a one-factor model with three observed variables corresponding to the scale items to be tested constituted a saturated model, which does not allow the evaluation of goodness of fit between the data and the model. Second, corrected item-total correlations and Cronbach's alphas were calculated using the data from Sample A and Sample B to assess the internal consistency reliability of the MLQ-SF-J. Third, test-retest reliability was examined using the data at Time 1 and Time 2 from the student sample (Sample A). Finally, construct validity was examined by assessing correlations between scores on the MLQ-SF-J, the hedonic and eudaimonic well-being measures, and purpose in life scale using the data from Sample A and Sample B.

\section{Results}

\subsection{Factor Structure}

Exploratory factor analysis was performed on the data from Sample A at Time 1 and Time 2 and Sample B. The Kaiser-Meyer-Olkin measures of sampling adequacy were $0.70,0.72$, and 0.71 , and Bartlett's tests of sphericity yielded 211.63, 275.11, and 540.22 ( $p s<0.01$ ), respectively. These findings supported the suitability of the data set for factor analysis. As shown in Table 1, the factor analysis with each sample extracted only one factor with eigenvalues greater than 1.0, accounting for more than $70 \%$ of the variance. The factor loadings of the items were all greater than 0.67 .

\subsection{Internal Consistency and Temporal Stability}

Table 2 shows the means, standard deviations, range of scores, corrected item-total correlations, and Cronbach's alphas for the MLQ-SF-J in each sample. The corrected item-total correlations were moderate to high ( 0.59 to 0.80 ). Cronbach's alphas for internal consistency reliability ranged from 0.80 to 0.86 and had similar values across the samples. The correlation between MLQ-SF-J scores at Time 1 and Time 2 in Sample 1 was high (0.70). Although the mean scores on the MLQ-SF-J for Sample A at Time 1 were significantly lower than those for Sample A at Time 2 and Sample B ( $p s<0.01$ ), the effect sizes of these differences were small ( $d s=0.20$ and 0.21 ).

\subsection{Correlations with Other Measure Scores}

The correlations between scores on the MLQ-SF-J and well-being measures are 
summarized in Table 3. In general, the correlations were in the expected direction and similar between the two samples. In both samples, MLQ-SF-J scores were moderately positively correlated with scores on the Satisfaction with Life Scale and Positive Affect Scale (0.39 to 0.46). Although correlations between scores on the MLQ-SF-J and Negative Affect Scale were negative and significant in both samples as expected, they were low in Sample A and moderate in Sample $\mathrm{B},-0.14$ and -0.43 , respectively. The Flourishing Scale scores were highly correlated with the MLQ-SF-J scores (0.63 and 0.68) in both samples. Likewise, there were high correlations between the Life Engagement Test and MLQ-SF-J scores (0.61 and 0.71).

Table 1. Factor loadings for exploratory factor analysis.

\begin{tabular}{ccccc}
\hline & & \multicolumn{2}{c}{ Sample A } & \\
\cline { 3 - 4 } & Item & Time 1 & Time 2 & Sample B \\
\hline \multirow{2}{*}{ Factor Loading } & 1 & 0.78 & 0.84 & 0.80 \\
& 2 & 0.82 & 0.91 & 0.83 \\
& 3 & 0.67 & 0.75 & 0.72 \\
Eigenvalue & & 2.14 & 2.38 & 2.28 \\
\% of variance & & 71.24 & 79.46 & 76.01 \\
\hline
\end{tabular}

Table 2. Means, standard deviations, range of scores, and cronbach's alphas of MLQSF-J.

\begin{tabular}{ccccccc}
\hline Sample & & M & SD & Range of Scores & CITC & Cronbach's $\alpha$ \\
\hline Sample A & Time 1 & 7.53 & 2.06 & $3-12$ & $0.59-0.68$ & 0.80 \\
& Time 2 & 7.94 & 2.10 & $3-12$ & $0.70-0.80$ & 0.86 \\
Sample B & & 7.94 & 1.76 & $3-12$ & $0.64-0.71$ & 0.84 \\
\hline
\end{tabular}

Note: CITC $=$ corrected item-total correlations

Table 3. Correlations between scores on MLQ-SF-J and well-being measures.

\begin{tabular}{ccccccc}
\hline Sample & Measure & $r$ & $95 \%$ CI & $M$ & $S D$ & Cronbach's $\alpha$ \\
\hline \multirow{2}{*}{ Satisfaction with Life Scale } & 0.39 & {$[0.31,0.48]$} & 13.29 & 3.46 & 0.73 \\
Sample A & Positive Affect Scale & 0.39 & {$[0.31,0.48]$} & 20.98 & 4.54 & 0.92 \\
& Negative Affect Scale & -0.14 & {$[-0.24,-0.04]$} & 17.25 & 4.46 & 0.80 \\
& Flourishing Scale & 0.63 & {$[0.56,0.68]$} & 36.16 & 7.05 & 0.81 \\
& Life Engagement Test & 0.61 & {$[0.54,0.67]$} & 21.05 & 4.42 & 0.85 \\
\hline \multirow{2}{*}{ Satisfaction with Life Scale } & 0.40 & {$[0.33,0.47]$} & 14.20 & 3.61 & 0.82 \\
& Positive Affect Scale & 0.46 & {$[0.38,0.54]$} & 20.08 & 4.82 & 0.92 \\
& Negative Affect Scale & -0.43 & {$[-0.50,-0.35]$} & 16.40 & 5.00 & 0.87 \\
& Flourishing Scale & 0.68 & {$[0.62,0.73]$} & 37.16 & 6.46 & 0.80
\end{tabular}

Note: All correlations are significant at $p<0.01$. 


\section{Discussion}

The aim of this study was to validate a Japanese translation of the MLQ-SF, which was designed as a brief measure to assess the presence of meaning in life. The data obtained from two independent samples were used to examine the psychometric properties of the MLQ-SF-J. The factor structure of the MLQ-SF-J was confirmed with exploratory factor analysis. Internal consistency reliability was examined using corrected item-total correlations and Cronbach's alphas. Test-retest reliability over a 4-week period was evaluated with the data from the student sample. Construct validity was examined by assessing correlations with scores for well-being.

The factor analysis identified a clear single factor structure, in common with the MLQ-SF (Steger \& Samman, 2012). This factor structure was found in both the student sample and the adult worker sample. The findings support the factorial validity of the MLQ-SF-J across the different samples. Additionally, temporal stability of the single-factor structure over a 4 -week period was found in the data from the student sample.

The internal consistency reliability of the MLQ-SF-J was deemed good, with Cronbach's alphas ranging from 0.80 to 0.86 , indicating values appropriate to a short form measure (Streiner, Norman, \& Cairney, 2015). The correlation between MLQ-SF-J scores at Time 1 and Time 2 in the student sample was 0.70. It was previously reported that the test-retest reliability coefficient of the Presence subscale of the MLQ was 0.70 over a 1-month period in an American sample (Steger et al., 2006), and that the coefficient of the Presence subscale of the Japanese version of the MLQ was 0.66 over a 4 -week period in a Japanese sample (Steger et al., 2008). These previous results are fairly similar to the present result. For this reason, good temporal stability of the MLQ-SF-J over a 4-week interval is supported.

The correlations with scores on the well-being measures provide support for the construct validity of the MLQ-SF-J. Although there were relatively large differences in the correlations of the MLQ-SF-J scores with the negative affect scores between the two samples, the correlations with the scores for the hedonic well-being measures generally show the expected relationships to the MLQ-SF-J scores in both samples. The MLQ-SF scores are moderately correlated with life satisfaction scores (Steger \& Samman, 2012). In addition, previous studies found that the Presence subscale scores of the MLQ had moderate to high correlations with life satisfaction scores ranging from 0.46 to 0.63 (Steger et al., 2006; Steger \& Kashdan, 2007), moderate correlations with positive affect (love and joy) scores, and low to moderate correlations with negative affect (fear, anger, shame, and sadness) scores (Steger et al., 2006). These correlations reported in previous studies are similar to those in the present study. Therefore, the present findings regarding the correlations support the convergent validity of the MLQ-SF-J.

As predicted, there was a high correlation between scores on the MLQ-SF-J and the measure of eudaimonic well-being, which includes meaning in life as a 
component (Keyes, Shmotkin, \& Ryff, 2002; Ryff \& Keyes, 1995; Steger, 2009). Furthermore, the MLQ-SF-J scores were highly or very highly correlated with scores for purpose in life, which is often supposed to have construct overlap with meaning in life (George \& Park, 2013; Ryff \& Keyes, 1995; Martela \& Steger, 2016), in common with eudaimonic well-being. These expected correlations were found in both college students and adult workers. Therefore, the results support the convergent validity of the MLQ-SF-J across the two samples. The values of reliability and the mean scores of the MLQ-SF-J, as well as its validity, were relatively similar between the student sample and the adult worker sample.

The findings of this study indicate that the MLQ-SF-J is a useful measure for assessing meaning in life with appropriate reliability and construct validity. However, several potential limitations of this study should be addressed. First, because the sample population was limited to college students and adult workers, the results may not be generalizable to other populations. The psychometric properties of the MLQ-SF-J should be further examined using various populations such as the elderly or clinical samples. Second, test-retest reliability was examined over a 4-week interval. In the future, the temporal stability of the MLQ-SF-J scores should be examined over longer intervals. Third, construct validity was examined through correlations with well-being measure scores. Future studies should examine associations with scores for various constructs and other aspects of psychometric properties, such as criterion-related validity.

Despite these limitations, this study provides preliminary but compelling evidence for the psychometric properties of the MLQ-SF-J. This measure is brief and convenient enough for easy use in large-scale research. The use of the MLQ-SF-J is expected to promote a greater understanding of meaning in life among Japanese people.

\section{Acknowledgements}

The kind permission to translate and reproduce the Meaning in Life Questionnaire-Short Form by Professor Michael F. Steger is appreciated.

\section{Funding}

This study was supported by JSPS KAKENHI Grant Number 15K04121

(https://www.jsps.go.jp/english/e-grants/).

\section{Conflicts of Interest}

The author declares no conflicts of interest regarding the publication of this paper.

\section{References}

Antonovsky, A. (1987). Unraveling the Mystery of Health: How People Manage Stress and Stay Well. San Francisco, CA: Jossey-Bass.

Battista, J., \& Almond, R. (1973). The Development of Meaning in Life. Psychiatry, 36, 
409-427. https://doi.org/10.1080/00332747.1973.11023774

Bloch, J. H., Farrell, J. E., Hook, J. N., Van Tongeren, D. R., Penberthy, J. K., \& Davis, D. E. (2017). The Effectiveness of a Meditation Course on Mindfulness and Meaning in Life. Spirituality in Clinical Practice, 4, 100-112. https://doi.org/10.1037/scp0000119

Brislin, R. W. (1970). Back-Translation for Cross-Cultural Research. Journal of CrossCultural Psychology, 1, 185-216. https://doi.org/10.1177/135910457000100301

Crumbaugh, J. C., \& Maholick, L. T. (1964). An Experimental Study in Existentialism: The Psychometric Approach to Frankl's Concept of Noogenic Neurosis. Journal of Clinical Psychology, 20, 200-207. https://doi.org/10.1002/1097-4679(196404)20:2<200::AID-JCLP2270200203>3.0.CO;2-U

Deci, E. L., \& Ryan, R. M. (2008). Hedonia, Eudaimonia, and Well-Being: An Introduction. Journal of Happiness Studies, 9, 1-11. https://doi.org/10.1007/s10902-006-9018-1

Diener, E, Emmons, R. A., Larsen, R. J., \& Griffin, S. (1985). The Satisfaction with Life Scale. Journal of Personality Assessment, 49, 71-75. https://doi.org/10.1207/s15327752jpa4901_13

Diener, E., \& Seligman, M. E. P. (2004). Beyond Money: Toward an Economy of Well-Being. Psychological Science in the Public Interest, 5, 1-31. https://doi.org/10.1111/j.0963-7214.2004.00501001.x

Diener, E., Lucas, R. E., \& Scollon, C. N. (2006). Beyond the Hedonic Treadmill: Revising the Adaptation Theory of Well-Being. American Psychologist, 61, 305-314.

https://doi.org/10.1037/0003-066X.61.4.305

Diener, E., Wirtz, D., Tov, W., Kim-Prieto, C., Choi, D. W., Oishi, S., \& Biswas-Diener, R. (2010). New Well-Being Measures: Short Scales to Assess Flourishing and Positive and Negative Feelings. Social Indicators Research, 97, 143-156. https://doi.org/10.1007/s11205-009-9493-y

George, L. S., \& Park, C. L. (2013). Are Meaning and Purpose Distinct? An Examination of Correlates and Predictors. Journal of Positive Psychology, 8, 365-375. https://doi.org/10.1080/17439760.2013.805801

Heintzelman, S. J., \& King, L. A. (2014a). Life Is Pretty Meaningful. American Psychologist, 69, 561-574. https://doi.org/10.1037/a0035049

Heintzelman, S. J., \& King, L. A. (2014b). (The Feeling of) Meaning-as-Information. Personality and Social Psychology Review, 18, 153-167. https://doi.org/10.1177/1088868313518487

Keyes, C. L. M., Shmotkin, D., \& Ryff, C. D. (2002). Optimizing Well-Being: The Empirical Encounter of Two Traditions. Journal of Personality and Social Psychology, 82, 1007-1022. https://doi.org/10.1037/0022-3514.82.6.1007

Martela, F., \& Steger, M. F. (2016). The Three Meanings of Meaning in Life: Distinguishing Coherence, Purpose, and Significance. Journal of Positive Psychology, 11, 531-545. https://doi.org/10.1080/17439760.2015.1137623

Ryan, R. M., \& Deci, E. L. (2001). On Happiness and Human Potentials: A Review of Research on Hedonic and Eudaimonic Well-Being. Annual Review of Psychology, 52, 141-166. https://doi.org/10.1146/annurev.psych.52.1.141

Ryff, C. D., \& Keyes, C. L. M. (1995). The Structure of Psychological Well-Being Revisited. Journal of Personality and Social Psychology, 69, 719-727. https://doi.org/10.1037/0022-3514.69.4.719

Ryff, C. D., \& Singer, B. H. (1998). The Contours of Positive Human Health. Psychological Inquiry, 9, 1-28. https://doi.org/10.1207/s15327965pli0901_1

Scheier, M. F., Wrosch, C., Baum, A., Cohen, S., Martire, L. M., Matthews, K. A., Schulz, 
R., \& Zdaniuk, B. (2006). The Life Engagement Test: Assessing Purpose in Life. Journal of Behavioral Medicine, 29, 291-298. https://doi.org/10.1007/s10865-005-9044-1

Seligman, M. E. P., \& Csikszentmihalyi, M. (2000). Positive Psychology: An Introduction. American Psychologist, 55, 5-14. https://doi.org/10.1037/0003-066X.55.1.5

Steger, F. M., \& Samman, E. (2012). Assessing Meaning in Life on an International Scale. International Journal of Wellbeing, 2, 182-195. https://doi.org/10.5502/ijw.v2i.i3.2

Steger, M. F. (2009). Meaning in Life. In S. J. Lopez, \& C. R. Snyder (Eds.), Oxford Handbook of Positive Psychology (2nd ed., pp. 679-687). Oxford, UK: Oxford University Press. https://doi.org/10.1093/oxfordhb/9780195187243.013.0064

Steger, M. F. (2012). Experiencing Meaning in Life: Optimal Functioning at the Nexus of Well-Being, Psychopathology, and Spirituality. In P. T. P. Wong (Ed.), The Human Quest for Meaning: Theories, Research, and Applications (2nd ed., pp. 165-184). New York: Routledge.

Steger, M. F., \& Kashdan, T. B. (2007). Stability and Specificity of Meaning in Life and Life Satisfaction over One Year. Journal of Happiness Studies, 8, 161-179.

https://doi.org/10.1007/s10902-006-9011-8

Steger, M. F., Frazier, P., Oishi, P., \& Kaler, M. (2006). The Meaning in Life Questionnaire: Assessing the Presence of and Search for Meaning in Life. Journal of Counseling Psychology, 53, 80-93. https://doi.org/10.1037/0022-0167.53.1.80

Steger, M. F., Kawabata, Y., Shimai, S., \& Otake, K. (2008). The Meaningful Life in Japan and the United States: Levels and Correlates of Meaning in Life. Journal of Research in Personality, 42, 660-678. https://doi.org/10.1016/j.jrp.2007.09.003

Steger, M. F., Shin, J. Y., Shim, Y., \& Fitch-Martin, A. (2013). Is Meaning in Life a Flagship Indicator of Well-Being? In A. S. Waterman (Ed.), The Best within Us: Positive Psychology Perspectives on Eudaimonia (pp. 159-182). Washington DC: American Psychological Association. https://doi.org/10.1037/14092-009

Streiner, D. L., Norman, G. R., \& Cairney, J. (2015). Health Measurement Scales: A Practical Guide to Their Development and Use (5th ed.). New York: Oxford University Press. https://doi.org/10.1093/med/9780199685219.001.0001

Sumi, K. (2008). Optimism, Pessimism, Social Support, and Psychological Adjustment: A Test of a Mediation Model. Journal of Educational and Health Science, 53, 119-125 [In Japanese].

Sumi, K. (2013). Reliability and Validity of Japanese Versions of the Flourishing Scale and the Scale of Positive and Negative Experience. Social Indicators Research, 118, 601-615. https://doi.org/10.1007/s11205-013-0432-6

Sumi, K. (2014). Temporal Stability of the Japanese Versions of the Flourishing Scale and the Scale of Positive and Negative Experience. Journal of Psychology and Psychotherapy, 4, 140. https://doi.org/10.4172/2161-0487.1000140

Sumi, K. (2018). The Japanese Translation of the Life Engagement Test: Reliability and Construct Validity in a College Student Population and a Working Adult Population. International Journal of Psychology and Behavior Analysis, 4, IJPBA-136. https://doi.org/10.15344/2455-3867/2018/136

Waterman, A. S. (1993). Two Conceptions of Happiness: Contrasts of Personal Expressiveness (Eudaimonia) and Hedonic Enjoyment. Journal of Personality and Social Psychology, 64, 678-691. https://doi.org/10.1037/0022-3514.64.4.678 